the fundus oculi itself it has been observed that the retinal changes in diabetes are apt to be complicated with hæmorrhages in the vitreous; the existence of a central scotoma in the visual field has also been noted. Neither of these conditions existed in the present case. The patient presented herself at the outdoor clinique of the Central London Ophthalmic Hospital on Nov. 11th, 1897, and the record of the case is as follows.

The patient was a woman, aged 67 years. She complained of failing sight for the past 12 months and of double vision which came on suddenly, and pain in the right eye had been present for three weeks. There was absolute paralysis of outward movement of the right eye. Each lens showed numerous peripheral strix (ordinary senile cataract). In the left fundus were two considerable patches consisting of yellowish white lustrous spots more or less confluent; each patch had a somewhat triangular or fan-shaped form, the apex being at the macula; there were also a number of isolated spots of a similar character scattered irregularly over the posterior part of the fundus. The right fundus appeared to be normal. There was no central scotoma in either visual field. The urine was pale, of specific gravity 1038, and contained a large quantity of sugar; there was no albumin. Physical examination of the thoracic and abdominal viscera was normal. Knee-jerks could not be obtained. The patient had enjoyed fairly good health except that within the last three years she had had two severe attacks of sciatica (each in the left limb) and six months ago she was confined to bed for some weeks with "weakness of the heart." Her husband died from angina pectoris 12 months ago. She had had nine children, of whom four had died from consumption. There was no history of gout or rheumatism in the family. She admitted that the daily amount of urine had been excessive for some six or seven years and that during the same time she had suffered from thirst; about four years ago she was told that she had diabetes.

The patient has been examined on several occasions since the above date. The urine has always had a specific gravity of 1030 or upwards and has contained much sugar; at no time has albumin been present. The paralysis of the right external rectus and the condition of the left fundus remained unchanged until the end of January, 1899, when the paresis had disappeared and the changes in the left fundus had become much more advanced; the right fundus still remained intact.

The diagnosis of the case is manifestly beyond dispute. The absence of albumin from the urine leaves the diabetic state entirely responsible for the condition of the fundus no less than for the peripheral nerve disturbances. These latter it will be noted include loss of the knee-jerks, paralysis of the right sixth nerve, and two severe attacks of sciatica. Saundby ${ }^{16}$ draws attention to the occurrence of sciatica in diabetic subjects and says that bilateral sciatica is especially suggestive of diabetes.

Chenies-street, w.o.

\section{THE EARLY DIAGNOSIS OF MYXCEDEMA.} BY CHARLES W. CHAPMAN, M.D. DURH., M.R.C.P. LOND.,

PHYSICIAN TO THE NATIONAL HOSPITAL FOR DISEASES OF THE HEART, SOHO-SQUARE.

ALTHOUGH the modern treatment of myxodema is most satisfactory, thanks to Mr. Victor Horsley, Dr. George R. Murray, and others who followed up von Eiselberg's experimental results, it is more than ever important that the disease should be diagnosed early, since thereby months or even years of incapacity for mental and physical work may be avoided. The clinical features of myxodema have been so frequently described that there is a danger of the practitioner failing to recognise the disease unless the case before him agrees entirely with those descriptions. The comparative rarity of cases of this disease increases the liability to their being overlooked. Again, patients may be under observation for long periods without the real cause of their illness being discovered. This is due to the insidious and chronic nature of the disease. Under such circumstances a correct diagnosis may at times be made by a stranger who sees the patient for

$$
{ }_{16}^{16} \text { Loc. cit. }
$$

the first time because his eyes have not been blinded by familiarity with the very gradual oncoming of this disease. This, at any rate, is the only way I can explain the nonrecognition of some cases of myxcedema that have come under my care. The following cases illustrate the difficulties of early diagnosis of myxudema and it will be noticed in the first and third cases that I failed to recognise the disease when first consulted.

CASE 1.-A woman, aged 27 years, a nurse, came under my care in March, 1894. Her mistress asked my advice because the woman had been out of health for some years, and although she had been under the care of some leading practitioners no real benefit had accrued from the treatment. The patient complained of increasing weakness, anæmia, faintings in which sometimes her knees gave way and caused her to fall, loss of appetite, and frequent unfitness for her duties. The bowels were costive and the catamenia were scanty and pale. The patient's health began to fail in 1888, when she was 21 years of age. She became pale then and remained so up to the time that my advice was sought and iron had been taken more or less continuously ever since with but little benefit. An examination revealed nothing morbid beyond a bronchial catarrh-in fact, the case had every appearance of ordinary chlorosis. As I did not glean that arsenic had been given as well as iron I prescribed both drugs in combination. I ordered a liberal diet and insisted on perseverance with the treatment for several weeks. Some little improvement followed. Nine months after the first consultation I was asked to see the patient again because she was rapidly getting worse. She was unable to walk upstairs and could only crawl up on her knees. She had, moreover, fallen several times. Her condition at this time at once suggested myxcedema. The face was puffy, the hair was scanty, the abdomen was enlarged to 30 inches, the memory was failing, and the urine was free from albumin. Thyroid treatment was at once commenced; an improvement soon set in and the case progressed in the manner now so familiar to us all. The patient has since married and, with the exception of a miscarriage, has kept well. At my request she came to see me on June 28th, 1899, and she showed no signs of a relapse.

OASE 2.-A woman, aged 59 years, came under my care at the National Hospital for Diseases of the Heart, Sohosquare, in September, 1896. She complained of giddiness during which she sometimes fell down, of inability to walk for more than five minutes at a time, of pain in the limbs and back, and of a sense of weight in the abdomen. She bad not been well for 20 years, and had been decidedly ill for the last seven years. Four years previously she had first noticed her hair getting thin and wiry, and two years afterwards her face began to swell, especially under the eyes. Other symptoms were those of failing memory and a disinclination to do anything. There were also pain and swelling of the hands and limbs and thickness of speech. She was constantly under the care of two medical men who treated her chiefly with arsenic. As she was worse after seven years' treatment she consulted a third medical man who told her that she had a fatty heart and might die at any moment. The patient was a very large woman. Her malar eminences and her nose were red and the other parts of her face were pale. Her hands were broad and swollen, and she was puffy under the eyes. Her hair was thin and wiry on the head and was absent in the axillæ and elsewhere. She exhibited the characteristic mental condition and the action of her heart was slow. The case was diagnosed as myxcedema and treated accordingly. The improvement was rapid and marked and in about three weeks she was approaching the standard of health which she had enjoyed many years previously. At the expiration of nine months the patient gave up treatment, but she was compelled to resume it before. long. In June, 1898, she was in perfect health.

CASE 3.-A woman, aged 42 years, came under my care in the National Hospital for Diseases of the Heart as an outpatient on Sept. 25th, 1897. She complained of præcordial pain, palpitation, and dyspnoea on exertion and she had to be propped up at night. She had not "been herself," she said, "for two years," and four months previously the symptoms began for which she sought advice. She had had rheumatic fever three years before. She was a big woman and rather pale; the tongue was flabby, the bowels were regular, and the catamenia were regular and excessive. Physical examination revealed nothing special beyond a feeble action of the heart and a little pulmonary catarrh. In the absence of any 
sign of valve lesion the patient was ordered an expectorant with small doses of digitalis, as it was thought that when the tone of the heart improved a bruit might be made out. In July, 1898, the patient went through a subacute attack of rheumatism. On her return to the hospital nothing fresh was observed in the heart. On May 12th, 1899, after an absence of ten months, she again presented herself and complained of giddiness which was s s severe at times that she had to seek supp rrt to prevent herself from falling. Her memory was failing and she felt very cold, and her hair, which had always been very thick, was rapidly falling off The heart's action was slow. The patient presented most of the usual signs of myxœedema, but the case was by no means a pronounced one. Thyroid treatment was at once adopled and an improvement was noted in the following week. In a fortnight the giddiness had disappeared entirely, by the end of June the hair was growing where it had been thin, and the patient said that she was quite well, able to attend to her household duties, and generally to lead an active life.

Remarks.-Case 1 shows that obstinate anæmia, even in a young woman, may be a forerunner of myxœdema and proves the importance of prompt action on the appearance of even one or two signs only of the latter disease. Certainly, when ever in the future I find an anæmic woman getting dull and falling about I shall watch carefully for any evidence of myxoedema. Case 2 emphasises the contentions contained in the early part of this paper. The patient's first two medical advisers probably looked upon the case as one of chronic anæmia which required a prolonged course of arsenic while the third medical man diagnosed a fatty heart and sounded the death-knell. In Case 3 the patient had had rheumatic fever and although there was no positive evidence of the presence of heart lesion yet the symptoms following such a history rendered the existence of heart disease a least probable. Cardiac toni ss were prescribed in the expectation that with returning strength a bruit might develop and so render the diagnosis more precise. In this, however, we were disappointed and it was not until the real cause of the patient's symptoms became more erident that a correct diagnosis was made.

I will conclude by calling attention to a diagnostic sign in early myxodema which has proved useful in my hands. In chronic renal disease an early sign, when looked out for, is a certain sloppiness of the conjunctiræ which is best observed by pushing up the lower eyelid at the outer angle of the eye. "This is known as "Bright's eye." In myxcedema a somewhat similar condition exists caused by the presence of mucin. When I find the conjunctivæ thus affected without any local cause I invariably examine the urine, and when this fluid is of normal specific gravity and is devoid of albumin I look out for myxcedema. I have more than once been put on the right track by these means.

Weymouth-street, W.

\section{THE MANAGEMENT OF THE DEFORMITY OF HIP-DISEASE.}

BY A. B. JUDSON, M.D.,

ORTHOPADIO SURGEON TO THE OUT-PATIENT DEPARTMENT OF THF NEW YORK HOSPITAL AND CHARRIIN OF THE ORTHOPADIC SECTION OF THE NEW YORK ACADEMY OF MEDICLNE.

THE desire to prevent or correct the deformity of hipdisease has given rise to a variety of operative and mechanical expedients. Among the latter I have applied with considerable satisfaction a method which may be said to consist in the education of the patient, wearing the American hip-splint, ${ }^{1}$ to the habitual observance of the normal rhythm of locomotion. This method was briefly stated in THE LANCET of Dec. 22nd, 1888, pp. 1225-27. Having had its value confirmed by further experience I desire to present the subject again and more in detail.

The deformity and factitious (not to be confounded with the bony) shortening may be said to be caused by the patient's effort to keep the affected limb clear of the ground by elevating the pelvis on that side with adduction and factitious shortening as necessary accompaniments (flexion and adduction are here considered in the same category)

I Transactions of the Ninth International Medical Congress, 1887 vol. iii., pp 642-645.
The patient does this to avoid sudden and unexpected contact of the painful foot with the ground and to withhold the disabled limb from the ground in favour of the sound one, which hastens at each recurring step to assume an undue share of the work of sustaining the weight of the body in locomotion. The result is that the affected foot visits the ground for a moment only while the otber foot lingers on the ground and the natural rbythn, or time, is destroyed. True time may be expressed as follows:

one-two-one-two-one-two-one-two-one-two,

and false time thus

$$
\begin{gathered}
\text { one-two-one-two- one-two-ore-two- } \\
\text { one-two-one-two. }
\end{gathered}
$$

It is found that if the patient gives up false time and resumes true time by an effort of the will or as the result of drill the affected limb gives up some of its adduction and flexion in order the more conveniently to reach the ground to do its share of the work. With this come horizontal adjustment of the pelvis and decrease of shortening.

Violation of rhythm and the deformity appear to be incidents of Nature's method of protecting the diseased joint from traumatism by transferring a large part of the work of locomotion from the affected limb to the sound one. One of the advantages of the splint is that it furnishes complete protection with a return to the natural rhythm. This will demand sufficient strength in the apparatus to give to the body the support which it is accustomed to receive from a limb that is not affected. Patients who had recovered with serious lameness when instructed in this matter have overcome a large part of their lameness and deformity by learning to observe natural time in walking, a change which could not be accepted, of course, if bony ankylosis was the result of hip-disease. It is an interesting fact that throughout the early and active stages of the disease the position of the limb readily yields without pain to a slight amount of continuous force. Even after recovery the condition is far from immobilisation or obstinate fixation.

It may be said, by the way, that the rhythm of human locomotion is a subject which has probably not received the attention to which it is entitled. The very simplicity of the normal rhythm makes a slight deviation very noticeable, as in the incipient lameness of a child, who simply accentuates the blow given to the ground by the hastening non-affected foot. Violation of rhythm is one of the constituents of lameness. Lameness in general is essentially asymmetrical walking, symmetry of gait requiring similarity of the two limbs, not only in length and relation to the rest of the body, but also in movement. It is a point of practical import. ance that the lame needlessly add to their lameness by neglecting to keep correct time with their feet. A person who is well can pass for lame by the simple device of giving more time to one foot than to the other - a matter capable of instant demonstration; and one who is seriously lame can lessen the appearance of being so by observing the natura rhythm of locomotion. An interesting and practical ques. tion forms itself thus: Why do patients similarly affected and treated alike recover with such different degrees of deformity? The method here presented is the result of seeking an answer to this question with the help of the light thrown on the suoject by facts like the following.

A young girl was in the third stage before treatment was begun. She recovered in due time with no adduction, almost no flexion, and very little lameness-a result apparently due to the fact that she was an only daughter and was always in the presence of her anxious mother, so that every step she took wearing the hip-splint was taken under the necessity of appearing as well as she could. Her steps were timed equally and the affected limb assumed and retained a useful position because it had to do, so far as was possible, one-half of the work of locomotion.

A boy recovered from the disease in a more moderate form, but he limped about most awkward]y with 20 degrees of adduction and 50 degrees of flexion-a bad position which is explicable by the fact that his mother, an accomplishtd and industrious woman, was out of the house every dav attending to business and leaving at home all day a family of four boys. As the patient was most of the time in excellent general health he shared all the games of his brothers and developed the limb which was well at the expense of the affected one, which was elevated and adducted to keep it out of the way.

Another patient who recovered after long-continued 